\title{
Opinion: Inhibition of Blood-Brain Barrier Repair as a Mechanism in HIV-1 Disease
}

\author{
Monique E. Maubert ${ }^{1}$, Brian Wigdahl ${ }^{1,2}$ and Michael R. Nonnemacher ${ }^{1 *}$ \\ ${ }^{1}$ Department of Microbiology and Immunology, and Center for Molecular Virology and Translational Neuroscience, Institute \\ for Molecular Medicine and Infectious Disease, Drexel University College of Medicine, Philadelphia, PA, USA, ${ }^{2}$ Sidney Kimmel \\ Cancer Center, Thomas Jefferson University, Philadelphia, PA, USA
}

Keywords: HIV-1, Tat, blood-brain barrier (BBB), NMDAR, VEGFR, c-Src

OPEN ACCESS

Edited by:

Tibor Hortobágyi,

University of Debrecen, Hungary

Reviewed by:

Venkata Subba Rao Atluri,

Florida International University, USA

${ }^{*}$ Correspondence:

Michael R. Nonnemacher

mmonnema@drexelmed.edu

Specialty section:

This article was submitted to

Neurodegeneration,

a section of the journal

Frontiers in Neuroscience

Received: 23 February 2017

Accepted: 05 April 2017

Published: 26 April 2017

Citation:

Maubert ME, Wigdahl $B$ and Nonnemacher MR (2017) Opinion: Inhibition of Blood-Brain Barrier Repair as a Mechanism in HIV-1 Disease.

Front. Neurosci. 11:228. doi: 10.3389/fnins.2017.00228
The blood-brain barrier (BBB) is a complex network of microvasculature, comprised primarily of brain microvascular endothelial cells (BMECs), astrocytes, and pericytes, which regulates cellular, macromolecule, and metabolite passage between the peripheral circulation and the central nervous system (CNS). Damage to the BBB has been linked to neurocognitive deficits sustained in multiple diseases, including stroke, Alzheimer's Disease, and numerous infections, including human immunodeficiency virus type 1 (HIV-1) (Krizanac-Bengez et al., 2004; Salmina et al., 2010; Logsdon et al., 2015). Although the development and deployment of anti-retroviral therapy (ART) has transformed HIV-1 infection from an acute terminal diagnosis to a chronic pharmaceuticallymanaged clinical condition (in the developed world), many clinical complications remain prevalent in HIV-1-infected patients, including the spectrum of neurocognitive deficits collectively termed HIV-1-associated neurocognitive disorders (HAND). While the current age of ART has decreased the occurrence of the more severe manifestations of neurocognitive impairment in patients, particularly with regards to the incidence of HIV-1-associated dementia (HAD), the overall prevalence of HAND has not subsided (Cysique et al., 2004; Robertson et al., 2007; Tozzi et al., 2007; Heaton et al., 2010, 2011; Cysique and Brew, 2011). In fact, it is currently estimated that nearly $50-70 \%$ of HIV-1-infected patients on a successful ART regimen experience some level of neurocognitive decline (Heaton et al., 2010, 2011, 2015; Simioni et al., 2010; Obermeit et al., 2017). Implicated in the development of HAND in patients is a combination of toxic viral proteins released into the CNS, a sustained host pro-inflammatory response in the CNS initiated by the virus, deregulated endogenous small molecule metabolism, detrimental metabolic byproducts associated with combination ART, as well as certain types of HIV-1 genetic variants that may cause some of these pathogenic processes (Krebs et al., 2000; Wang et al., 2006; Ferrucci et al., 2011, 2012; Strazza et al., 2011; Dahiya et al., 2013; Aiamkitsumrit et al., 2014; Gresele et al., 2014; Maubert et al., 2015; Dampier et al., 2017; James et al., 2016).

Numerous in vitro and in vivo models have demonstrated molecular deregulation and functional impairment of the BBB in the context of HIV-1 infection, including downregulation of key tight junction complex components and upregulation of cell adhesion molecules on BMECs, aberrant activation of astrocytes and pericytes, overall increased permeability, and enhanced immune cell passage across the barrier (Toborek et al., 2005; Li et al., 2009; Roberts et al., 2010; Debaisieux et al., 2012; Louboutin and Strayer, 2012; Nakagawa et al., 2012; Bagashev and Sawaya, 2013; Niu et al., 2014; Rao et al., 2014; Hong and Banks, 2015; Maubert et al., 2015). However, while multiple HIV-1 proteins (including Tat, gp120, Vpr, and Nef) have been shown to deregulate numerous pathways resulting in damage to the BBB, the role of HIV-1 in modulating the pathways relative to the repair of the $\mathrm{BBB}$ and re-endothelialization (or the inhibition, thereof) have not yet been reported in detail. 
Clinically, endothelial cell dysfunction and general wound repair has been problematic in the HIV-1-infected patient population, with several reports highlighting delays in healing time and related complications, including secondary infections of these wounds (Lord, 1997; Davis et al., 1999; Diz Dios et al., 1999; Miyamoto et al., 2006; Arildsen et al., 2013; Wang et al., 2013; Francisci et al., 2014; Balsam et al., 2015; Fitzpatrick et al., 2016). While the mechanisms orchestrating endothelial repair, particularly considering those of the $\mathrm{BBB}$, are not entirely defined, some molecular effectors and interconnecting pathways have been identified in the literature for their demonstrated involvement in repair processes in various model systems. In particular, cellular Src kinase (c-Src), a ubiquitously expressed member of the Src family of non-receptor tyrosine kinases, has a defined role in endothelial cell regulation and repair, both in vitro and in vivo (Takenaga et al., 2009; Liu et al., 2010; Franco et al., 2013; Bai et al., 2014; Cao et al., 2015), the specifics of which are described below. Importantly, c-Src is involved in pathways linked to the activation of vascular endothelial growth factor receptor 2 (VEGFR2) and N-methyl D-aspartate receptor (NMDAR), both of which are expressed on human BMECs and with demonstrated roles in BBB regulation and integrity (Sharp et al., 2003, 2005; Andras et al., 2007; Holmes et al., 2007; Davis et al., 2010; Reijerkerk et al., 2010; Hudson et al., 2014; Chen et al., 2016; Fearnley et al., 2016).

Of note, HIV-1 infection and c-Src activation have been shown to have a reciprocal relationship in the literature with reports demonstrating that c-Src activation was increased in human Jurkat T cells $24 \mathrm{~h}$ after HIV-1 infection (Phipps et al., 1996) and in activated primary human CD4 $\mathrm{T}$ cells within $1 \mathrm{~h}$ of infection, as compared to uninfected controls, and that both chemical inhibition and siRNA knockdown of c-Src decreased infectivity of Nef-deficient HIV-1 reporter viruses by more than $50 \%$ in primary human CD4 $\mathrm{T}$ cells, in vitro (McCarthy et al., 2016). In addition, siRNA knockdown of c-Src decreased proviral integration of Nef-competent X4 and R5 HIV-1 laboratory strains by several-fold and significantly attenuated replication of these viral strains in primary human CD4 $\mathrm{T}$ cells, in vitro (McCarthy et al., 2016). While this observation links c-Src to HIV-1 infection in cells, it is known that BMECs and endothelial cells in general are not infected.

Given this point, it is more likely that extracellular viral proteins would interact with the BMECs causing dysfunction or inhibiting repair. At the level of isolated viral proteins, previous reports have indicated that HIV-1 gp120 can activate the NMDAR through direct binding of NMDAR subunits (Xin et al., 1999) in numerous in vitro systems, including in primary rat (Pattarini et al., 1998) and human (Pittaluga et al., 1996) neuronal synaptosomes; indirect activation of the NMDAR by gp120 exposure through the enhanced secretion of NMDAR agonists from proximal glia (Meucci and Miller, 1996) as well as activation of other receptor-mediated pathways which affect NMDAR activity in primary rat cultures (Xu et al., 2011) has also been reported. Additionally, it has been demonstrated that HIV1 Nef activates c-Src in an in vitro yeast model system (Trible et al., 2006; Narute and Smithgall, 2012). Most strikingly, though, c-Src, VEGFR2, and NMDAR have all been shown to be activated by exposure to HIV-1 Tat protein in a number of cell types, suggesting that Tat may be involved in inhibiting the mechanisms of $\mathrm{BBB}$ repair in HIV-1 disease. With respect to Tat, this may be of particular importance in ART-suppressed patients given recent evidence that shows Tat can be detected in cells, cerebral spinal fluid, and plasma of these individuals (Falkensammer et al., 2007; Mediouni et al., 2012; Bachani et al., 2013).

To further support the role of $\mathrm{c}$-Src in BBB health and repair, it has been reported that inhibition of $\mathrm{c}-\mathrm{Src}$ by siRNA limited permeability of human umbilical vein endothelial cells (HUVEC) exposed to vascular endothelial growth factor (VEGF, a known inducer of permeability of the BBB; Holmes et al., 2007; Davis et al., 2010; Hudson et al., 2014; Cao et al., 2015; Fearnley et al., 2016). In addition, chemical inhibition of cSrc with the inhibitor 1-(1,1-dimethylethyl)-3-(4-methylphenyl)$1 \mathrm{H}$-pyrazolo[3,4-d]pyrimidin-4-amine (PP1) accelerated healing of wounded HUVEC (Franco et al., 2013), in vitro. Furthermore, in vivo treatment with the broad Src family inhibitor 4-amino5-(4-chlorophenyl)-7-(t-butyl)-pyrazolo[3,4-d]pyrimidine (PP2) in rats subjected to ischemic insult resulted in the rescue of ischemic BBB leakage (Takenaga et al., 2009) and improved neurological deficit scores (Bai et al., 2014) in the presence of the inhibitor. Moreover, c-Src has been identified as an upstream regulator of a number of tight junction complex components, including occludin (Takenaga et al., 2009), claudin-5 (Bai et al., 2014), and zona occludens-1 (Morin-Brureau et al., 2011), as well as a modulator of NMDAR activity in neurons (Lu et al., 1999; Yu and Salter, 1999; Rong et al., 2001; Heidinger et al., 2002; Hossain et al., 2012; Tang et al., 2012; Krogh et al., 2014), and a downstream effector of the VEGFR2 signaling pathway (He et al., 1999; Morin-Brureau et al., 2011; Sun et al., 2012; Cao et al., 2015), in addition to its role in cell cycle regulation and proliferation (Boggon and Eck, 2004; Parsons and Parsons, 2004; $\mathrm{Hu}$ et al., 2008; Sen and Johnson, 2011; Reinecke and Caplan, 2014).

Structurally, c-Src is comprised of several domains, including a myristoylated membrane-targeting $\mathrm{SH} 4$ domain at the $\mathrm{N}$ terminus, followed by a unique domain, a SH3 domain, a $\mathrm{SH} 2$ domain, a kinase-linker region, a SH1 kinase domain bearing the activating tyrosine site (Y416), and a C-terminus bearing the inhibiting tyrosine site (Y529) (Boggon and Eck, 2004; Parsons and Parsons, 2004; Reinecke and Caplan, 2014). It has been previously reported that protein binding of the $\mathrm{SH} 3$ domain orchestrates the physical shift necessary to induce the active conformation of c-Src (Alexandropoulos and Baltimore, 1996). Interestingly, it has previously been shown that HIV1 Tat binds SH3 domains (Rom et al., 2011), and additional results have demonstrated that Tat exposure activates c-Src in primary rat neurons (Krogh et al., 2014), in a fetal bovine aortic endothelial cell line (Urbinati et al., 2005), and in human renal endothelial cells in the presence of growth factors (Das et al., 2016), supporting the hypothesis that HIV-1 Tat may delay BBB repair through the activation of $\mathrm{c}$-Src in human BMECs.

In addition, characterization of the ubiquitously-expressed cSrc promotor revealed several consensus Sp1 transcription start sites (Bonham and Fujita, 1993) and further analysis confirmed that transcriptional regulation of $\mathrm{c}$-Src is dependent on Sp1 


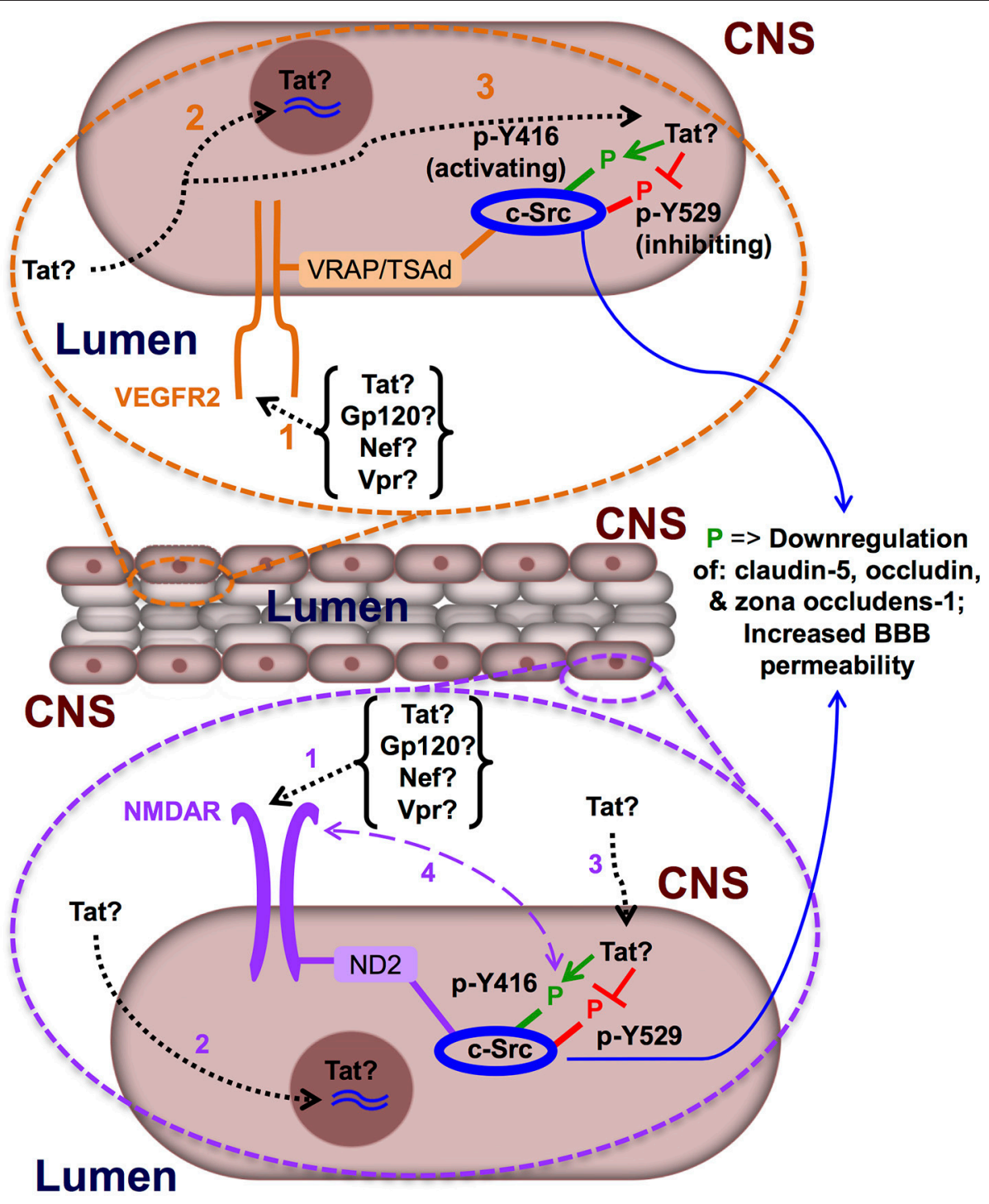

FIGURE 1 | Hypothetical model of the mechanisms underlying delayed blood-brain barrier repair in HIV-1 infection. Differential expression of VEGFR2 has been proposed and demonstrated on the lumen- and CNS-exposed surfaces of primary rat BMECs, in vitro (Hudson et al., 2014), lending to the possibility that this receptor may be activated by HIV-1 proteins flowing in the peripheral circulation, as well as those generated in the CNS; here, we illustrate expression of VEGFR2 on the lumen-exposed surface (orange bubble). Polarized expression of NMDAR on BMECs has not been addressed in the literature; however, in consideration that the ligands which would activate this receptor are readily found in the CNS and secreted by astrocytes (a component of the BBB in adjacent proximity with BMECs), we presume and illustrate here expression of NMDAR on the CNS-exposed surface (purple bubble). (1) HIV-1 proteins (Tat, gp120, Vpr, or Nef) bind and activate the VEGFR2 and/or NMDAR, stimulating the receptor(s) and resulting in activation of c-Src (which is associated with these receptors via adaptor proteins*), leading to a signaling cascade which is linked to downregulated expression of tight junction complex components (i.e., claudin-5, occludin, and zona occludens-1) and increased BBB permeability. (2) HIV-1 Tat protein enters BMECs and traffics to the nucleus (by its encoded nuclear localization signal) and upregulates expression of c-Src at the transcriptional level via direct modulation of Sp1 activity at the c-Src promotor. (3) HIV-1 Tat protein that enters BMECs may also be retained in the cytosol and directly bind the SH3 domain of c-Src, thus orchestrating the physical shift necessary to induce the active conformation of c-Src (i.e., phosphorylation at Y416 and de-phosphorylation at Y529) and leading to inhibition of BBB repair. (4) In addition, there may be super-activation of the NMDAR via a feedback loop between the ligand-binding face of NMDAR and cytosolic receptor-associated c-Src. Adaptor proteins: VRAP, VEGF receptor associated protein; TSAd, T-cell specific adaptor molecule; ND2, NADH dehydrogenase subunit 2.

activity at the promotor (Ritchie et al., 2000). The relationship of Tat with $\mathrm{Sp} 1$ in the transcriptional regulation of the HIV-1 LTR, in addition to the regulation of several host genes, has been extensively explored in the literature (Harrich et al., 1989; Jeang et al., 1993; Majello et al., 1994; Lim and Garzino-Demo, 2000;
Burnett et al., 2009; Miller-Jensen et al., 2013; Kukkonen et al., 2014). In addition, it has been reported that Tat promotes Sp1 phosphorylation and activity and that this is orchestrated by Tat in a DNA-PK (double-stranded DNA-dependent protein kinase)dependent manner (Chun et al., 1998). These reports altogether 
suggest that Tat may also influence expression of c-Src at the transcriptional level by direct modulation of Sp1 activity at the c-Src promotor.

Previous reports have demonstrated that cytosolic c-Src localizes primarily with membrane-bound structures (Sen and Johnson, 2011; Reinecke and Caplan, 2014), and is documented to associate via adaptor proteins at the plasma membrane with both VEGFR2 (Holmes et al., 2007; Sun et al., 2012) and NMDAR (Yu and Salter, 1999; Rong et al., 2001; Hossain et al., 2012). VEGFR2 is a transmembrane receptor tyrosine kinase expressed primarily on vascular endothelial cells, including BMECs of the $\mathrm{BBB}$, and is activated by several identified ligands collectively termed VEGFs (Holmes et al., 2007; Zhang et al., 2013; Fearnley et al., 2016). In general, activation of VEGFR2 has been shown to induce leakiness of the $\mathrm{BBB}$, both in vivo and in vitro (Davis et al., 2010; Hudson et al., 2014). HIV-1 Tat-induced activation of VEGFR2 and related endothelial compromise has also been demonstrated (Albini et al., 1996; Ganju et al., 1998; Mitola et al., 2000; Arese et al., 2001; Andras et al., 2005). Of note, both in vivo and in vitro, VEGFR2 activation has been linked with activation of c-Src in numerous endothelial cell types (He et al., 1999; Morin-Brureau et al., 2011; Sun et al., 2012; Cao et al., 2015), and Tat exposure has been shown to mediate VEGFR2-initiated activation of c-Src in endothelial cells (Urbinati et al., 2005; Das et al., 2016). Taken together, these reports have strongly suggested a causal link between Tat exposure, VEGFR2 activation, and c-Src activation in endothelial cells of the $\mathrm{BBB}$, which may potentially inhibit BBB repair in patients, which has not yet been reported.

NMDAR is a transmembrane ionotropic glutamate receptor highly expressed in the CNS and characterized primarily in neurons (Kopke et al., 1993; Lee et al., 2014). Recently, expression of functional NMDAR on BMECs has been identified and a demonstration of NMDAR activation resulting in $\mathrm{BBB}$ compromise has been made in vitro (Sharp et al., 2003, 2005; Andras et al., 2007; Reijerkerk et al., 2010; Chen et al., 2016). Notably, NMDAR activation is itself regulated by c-Src phosphorylation of the NR2 subunits of the NMDAR (Yu and Salter, 1999; Rong et al., 2001; Hossain et al., 2012; Tang et al., 2012), and exogenous Tat-induced activation of NMDAR in rat neurons, in vitro, has been reported (Haughey et al., 2001; Song et al., 2003; Krogh et al., 2014). This includes a report that showed Tat-mediated activation of NMDAR in neurons is through Tat activation of c-Src (Krogh et al., 2014). In addition to this, a reciprocal activation between NMDAR and $\mathrm{c}$-Src has been demonstrated in primary rat neuronal cultures. This works through activation of NMDAR which causes a $\mathrm{Ca}^{2+}$ influx that activates nitric oxide synthase (NOS) and thus generates nitric oxide (NO). This leads to an induction of the S-nitrosylation of c-Src, which then promotes the auto-phosphorylation of c-Src at the activating tyrosine (Y416), which further phosphorylates the NR2A subunit of NMDAR (Tang et al., 2012). All of this is additionally complicated by a report which demonstrated HIV-1 Tat subtype-specific toxicity of primary rat neurons and NMDAR-expressing HEK cells, wherein markedly decreased cell survival was observed in cultures exposed to recombinant subtype B Tat as compared to subtype C Tat (Li et al., 2008). These observations were attributed to the cysteine to serine variation at position 31 of Tat that has been previously documented between these subtypes, and it was determined that this amino acid difference influenced the ability of Tat to interact with and activate the NMDAR (Li et al., 2008). Taken together, these reports imply an important relationship between HIV-1 Tat exposure, Tat genetics, c-Src activation, and NMDAR activation in endothelial cells of the $\mathrm{BBB}$, which may hinder $\mathrm{BBB}$ repair mechanisms, which has not previously been reported.

In summary, as a dynamic biological structure tasked with mediating communication between the CNS and the peripheral circulation, proper regulation of the $\mathrm{BBB}$ is critical to the maintenance of homeostasis in the CNS, and perturbations of the mechanisms in place which maintain this dynamic regulation are implicated in the incidence of a number of neurological diseases in humans, including HAND. The literature provides evidence that demonstrates that BBB damage does indeed occur in HIV1 CNS disease, and that this damage correlates to the spectrum of HAND outcomes reported in patients, however, whether these issues are compounded by a mechanistic inhibition of BBB repair in these patients, has not yet been documented. In addition, it is unclear as to whether the nature of the damage, the initiator of the damage, and whether the precise location or compartment where the damage has occurred are of distinct importance in the context of inhibition of the BBB repair mechanism proposed herein. Given these observations, understanding how extracellular HIV1 proteins, HIV-1-infected cells, and/or how support cells of the $\mathrm{BBB}$ (i.e., astrocytes, pericytes) alter the repair of the BBB and whether the regulation of $\mathrm{c}-\mathrm{Src}$ is at the center of this question is an open area of significant research to understanding the mechanisms that underlie HIV-1 neuropathogenesis and HAND (Figure 1).

\section{AUTHOR CONTRIBUTIONS}

$\mathrm{MM}, \mathrm{BW}$, and $\mathrm{MN}$ all made substantial contributions to the conception or design of the work, drafted the work and revised it critically for important intellectual content, provided final approval of the version to be published, and agree to be accountable for all aspects of the work in ensuring that questions related to the accuracy or integrity of any part of the work are appropriately investigated and resolved.

\section{FUNDING}

These studies were funded in part by the Public Health Service, National Institutes of Health, through grants from the National Institute of Neurological Disorders and Stroke (NS089435, $\mathrm{MN}$, Principal Investigator), the National Institute of Drug Abuse (DA19807, BW, Principal Investigator), National Institute of Mental Health (MH110360, BW Principal Investigator), Comprehensive NeuroAIDS Center (CNAC) (P30 MH092177, Kamel Khalili, PI; BW, PI of the Drexel subcontract for the Clinical and Translational Research Support Core), and under the Ruth L. Kirschstein National Research Service Award T32 MH079785 (BW, Principal Investigator of the Drexel University College of Medicine component and Dr. Olimpia Meucci 
as Co-Director). The contents of the paper are solely the responsibility of the authors and do not necessarily represent the official views of the NIH. MN was also supported by faculty

\section{REFERENCES}

Aiamkitsumrit, B., Dampier, W., Antell, G., Rivera, N., Martin-Garcia, J., Pirrone, V., et al. (2014). Bioinformatic analysis of HIV-1 entry and pathogenesis. Curr. HIV Res. 12, 132-161. doi: 10.2174/1570162X12666140526121746

Albini, A., Soldi, R., Giunciuglio, D., Giraudo, E., Benelli, R., Primo, L., et al. (1996). The angiogenesis induced by HIV-1 tat protein is mediated by the Flk-1/KDR receptor on vascular endothelial cells. Nat. Med. 2, 1371-1375. doi: $10.1038 / \mathrm{nm} 1296-1371$

Alexandropoulos, K., and Baltimore, D. (1996). Coordinate activation of c-Src by SH3- and SH2-binding sites on a novel p130Cas-related protein, Sin. Genes Dev. 10, 1341-1355. doi: 10.1101/gad.10.11.1341

Andras, I. E., Deli, M. A., Veszelka, S., Hayashi, K., Hennig, B., and Toborek, M. (2007). The NMDA and AMPA/KA receptors are involved in glutamate-induced alterations of occludin expression and phosphorylation in brain endothelial cells. J. Cereb. Blood Flow Metab. 27, 1431-1443. doi: $10.1038 /$ sj.jcbfm. 9600445

Andras, I. E., Pu, H., Tian, J., Deli, M. A., Nath, A., Hennig, B., et al. (2005). Signaling mechanisms of HIV-1 Tat-induced alterations of claudin-5 expression in brain endothelial cells. J. Cereb. Blood Flow Metab. 25, 1159-1170. doi: $10.1038 /$ sj.jcbfm. 9600115

Arese, M., Ferrandi, C., Primo, L., Camussi, G., and Bussolino, F. (2001). HIV-1 Tat protein stimulates in vivo vascular permeability and lymphomononuclear cell recruitment. J. Immunol. 166, 1380-1388. doi: 10.4049/jimmunol.166.2.1380

Arildsen, H., Sorensen, K. E., Ingerslev, J. M., Ostergaard, L. J., and Laursen, A. L. (2013). Endothelial dysfunction, increased inflammation, and activated coagulation in HIV-infected patients improve after initiation of highly active antiretroviral therapy. HIV Med. 14, 1-9. doi: 10.1111/j.1468-1293.2012.01027.x

Bachani, M., Sacktor, N., McArthur, J. C., Nath, A., and Rumbaugh, J. (2013). Detection of anti-tat antibodies in CSF of individuals with HIV-associated neurocognitive disorders. J. Neurovirol. 19, 82-88. doi: 10.1007/s13365-012-0144-8

Bagashev, A., and Sawaya, B. E. (2013). Roles and functions of HIV-1 Tat protein in the CNS: an overview. Virol. J. 10:358. doi: 10.1186/1743-422X-10-358

Bai, Y., Xu, G., Xu, M., Li, Q., and Qin, X. (2014). Inhibition of Src phosphorylation reduces damage to the blood-brain barrier following transient focal cerebral ischemia in rats. Int. J. Mol. Med. 34, 1473-1482. doi: 10.3892/ijmm.2014.1946

Balsam, P., Mikula, T., Peller, M., Suchacz, M., Puchalski, B., Koltowski, L., et al. (2015). Evaluation of endothelial function and arterial stiffness in HIV-infected patients: a pilot study. Kardiol. Pol. 73, 344-351. doi: 10.5603/KP.a2014.0231

Boggon, T. J., and Eck, M. J. (2004). Structure and regulation of Src family kinases. Oncogene 23, 7918-7927. doi: 10.1038/sj.onc.1208081

Bonham, K., and Fujita, D. J. (1993). Organization and analysis of the promoter region and $5^{\prime}$ non-coding exons of the human c-src proto-oncogene. Oncogene 8, 1973-1981.

Burnett, J. C., Miller-Jensen, K., Shah, P. S., Arkin, A. P., and Schaffer, D. V. (2009). Control of stochastic gene expression by host factors at the HIV promoter. PLoS Pathog. 5:e1000260. doi: 10.1371/journal.ppat.1000260

Cao, H. J., Zheng, L. Z., Wang, N., Wang, L. Y., Li, Y., Li, D., et al. (2015). Src blockage by siRNA inhibits VEGF-induced vascular hyperpemeability and osteoclast activity - an in vitro mechanism study for preventing destructive repair of osteonecrosis. Bone 74, 58-68. doi: 10.1016/j.bone.2014.12.060

Chen, J. T., Chen, T. G., Chang, Y. C., Chen, C. Y., and Chen, R. M. (2016). Roles of NMDARs in maintenance of the mouse cerebrovascular endothelial cell-constructed tight junction barrier. Toxicology 339, 40-50. doi: 10.1016/j.tox.2015.11.006

Chun, R. F., Semmes, O. J., Neuveut, C., and Jeang, K. T. (1998). Modulation of Sp1 phosphorylation by human immunodeficiency virus type 1 Tat. J. Virol. 72, 2615-2629.

Cysique, L. A., and Brew, B. J. (2011). Prevalence of non-confounded HIV-associated neurocognitive impairment in the context of plasma HIV RNA suppression. J. Neurovirol. 17, 176-183. doi: 10.1007/s13365-0110021-x development funds provided by the Department of Microbiology and Immunology and the Institute for Molecular Medicine and Infectious Disease.

Cysique, L. A., Maruff, P., and Brew, B. J. (2004). Prevalence and pattern of neuropsychological impairment in human immunodeficiency virusinfected/acquired immunodeficiency syndrome (HIV/AIDS) patients across pre- and post-highly active antiretroviral therapy eras: a combined study of two cohorts. J. Neurovirol. 10, 350-357. doi: 10.1080/13550280490521078

Dahiya, S., Irish, B. P., Nonnemacher, M. R., and Wigdahl, B. (2013). Genetic variation and HIV-associated neurologic disease. Adv. Virus Res. 87, 183-240. doi: 10.1016/B978-0-12-407698-3.00006-5

Dampier, W., Antell, G. C., Aiamkitsumrit, B., Nonnemacher, M. R., Jacobson, J. M., Pirrone, V., et al. (2017). Specific amino acids in HIV-1 Vpr are significantly associated with differences in patient neurocognitive status. J. Neurovirol. 23 , 113-124. doi: 10.1007/s13365-016-0462-3

Das, J. R., Gutkind, J. S., and Ray, P. E. (2016). Circulating fibroblast growth factor-2, HIV-tat, and vascular endothelial cell growth factor-A in HIV-infected children with renal disease activate rho-A and src in cultured renal endothelial cells. PLoS ONE 11:e0153837. doi: 10.1371/journal.pone.0153837

Davis, B., Tang, J., Zhang, L., Mu, D., Jiang, X., Biran, V., et al. (2010). Role of vasodilator stimulated phosphoprotein in VEGF induced blood-brain barrier permeability in endothelial cell monolayers. Int. J. Dev. Neurosci. 28, 423-428. doi: 10.1016/j.ijdevneu.2010.06.010

Davis, P. A., Corless, D. J., Gazzard, B. G., and Wastell, C. (1999). Increased risk of wound complications and poor healing following laparotomy in HIVseropositive and AIDS patients. Dig. Surg. 16, 60-67. doi: 10.1159/000018695

Debaisieux, S., Rayne, F., Yezid, H., and Beaumelle, B. (2012). The ins and outs of HIV-1 Tat. Traffic 13, 355-363. doi: 10.1111/j.1600-0854.2011.01286.x

Diz Dios, P., Fernandez Feijoo, J., and Vazquez Garcia, E. (1999). Tooth extraction in HIV sero-positive patients. Int. Dent. J. 49, 317-321. doi: 10.1111/j.1875-595X.1999.tb00531.x

Falkensammer, B., Freissmuth, D., Hubner, L., Speth, C., Dierich, M. P., and Stoiber, H. (2007). Changes in HIV-specific antibody responses and neutralization titers in patients under ART. Front. Biosci. 12, 2148-2158. doi: $10.2741 / 2218$

Fearnley, G. W., Smith, G. A., Abdul-Zani, I., Yuldasheva, N., Mughal, N. A., Homer-Vanniasinkam, S., et al. (2016). VEGF-A isoforms program differential VEGFR2 signal transduction, trafficking and proteolysis. Biol. Open 5, 571-583. doi: $10.1242 /$ bio. 017434

Ferrucci, A., Nonnemacher, M. R., and Wigdahl, B. (2011). Human immunodeficiency virus viral protein $\mathrm{R}$ as an extracellular protein in neuropathogenesis. Adv. Virus Res. 81, 165-199. doi: 10.1016/B978-0-12385885-6.00010-9

Ferrucci, A., Nonnemacher, M. R., Cohen, E. A., and Wigdahl, B. (2012). Extracellular human immunodeficiency virus type 1 viral protein $\mathrm{R}$ causes reductions in astrocytic ATP and glutathione levels compromising the antioxidant reservoir. Virus Res. 167, 358-369. doi: 10.1016/j.virusres. 2012.06.002

Fitzpatrick, M. E., Nouraie, M., Gingo, M. R., Camp, D., Kessinger, C. J., Sincebaugh, J. B., et al. (2016). Novel relationships of markers of monocyte activation and endothelial dysfunction with pulmonary dysfunction in HIV infected persons. AIDS 30, 1327-1339. doi: 10.1097/QAD.0000000000001092

Francisci, D., Falcinelli, E., Baroncelli, S., Petito, E., Cecchini, E., Weimer, L. E., et al. (2014). Potential anti-inflammatory effects of maraviroc in HIV-positive patients: a pilot study of inflammation, endothelial dysfunction, and coagulation markers. Scand. J. Infect. Dis. 46, 466-470. doi: $10.3109 / 00365548.2014 .898332$

Franco, D., Milde, F., Klingauf, M., Orsenigo, F., Dejana, E., Poulikakos, D., et al. (2013). Accelerated endothelial wound healing on microstructured substrates under flow. Biomaterials 34, 1488-1497. doi: 10.1016/j.biomaterials. 2012.10.007

Ganju, R. K., Munshi, N., Nair, B. C., Liu, Z. Y., Gill, P., and Groopman, J. E. (1998). Human immunodeficiency virus Tat modulates the Flk-1/KDR receptor, mitogen-activated protein kinases, and components of focal adhesion in Kaposi's sarcoma cells. J. Virol. 72, 6131-6137.

Gresele, P., Falcinelli, E., Momi, S., Francisci, D., and Baldelli, F. (2014). Highly active antiretroviral therapy-related mechanisms of endothelial and 
platelet function alterations. Rev. Cardiovasc. Med. 15(Suppl. 1), S9-20. doi: 10.3908.ricm15S1S004

Harrich, D., Garcia, J., Wu, F., Mitsuyasu, R., Gonazalez, J., and Gaynor, R. (1989). Role of SP1-binding domains in in vivo transcriptional regulation of the human immunodeficiency virus type 1 long terminal repeat. J. Virol. 63, 2585-2591.

Haughey, N. J., Nath, A., Mattson, M. P., Slevin, J. T., and Geiger, J. D. (2001). HIV-1 Tat through phosphorylation of NMDA receptors potentiates glutamate excitotoxicity. J. Neurochem. 78, 457-467. doi: 10.1046/j.14714159.2001.00396.x

He, H., Venema, V. J., Gu, X., Venema, R. C., Marrero, M. B., and Caldwell, R. B. (1999). Vascular endothelial growth factor signals endothelial cell production of nitric oxide and prostacyclin through flk-1/KDR activation of c-Src. J. Biol. Chem. 274, 25130-25135. doi: 10.1074/jbc.274.35.25130

Heaton, R. K., Clifford, D. B., Franklin, D. R. Jr., Woods, S. P., Ake, C., Vaida, F., et al. (2010). HIV-associated neurocognitive disorders persist in the era of potent antiretroviral therapy: CHARTER Study. Neurology 75, 2087-2096. doi: 10.1212/WNL.0b013e318200d727

Heaton, R. K., Franklin, D. R. Jr., Deutsch, R., Letendre, S., Ellis, R. J., Casaletto, K., et al. (2015). Neurocognitive change in the era of HIV combination antiretroviral therapy: the longitudinal CHARTER study. Clin. Infect. Dis. 60, 473-480. doi: 10.1093/cid/ciu862

Heaton, R. K., Franklin, D. R., Ellis, R. J., McCutchan, J. A., Letendre, S. L., Leblanc, S., et al. (2011). HIV-associated neurocognitive disorders before and during the era of combination antiretroviral therapy: differences in rates, nature, and predictors. J. Neurovirol. 17, 3-16. doi: 10.1007/s13365-0100006-1

Heidinger, V., Manzerra, P., Wang, X. Q., Strasser, U., Yu, S. P., Choi, D. W., et al. (2002). Metabotropic glutamate receptor 1-induced upregulation of NMDA receptor current: mediation through the $\mathrm{Pyk} 2 / \mathrm{Src}$-family kinase pathway in cortical neurons. J. Neurosci. 22, 5452-5461.

Holmes, K., Roberts, O. L., Thomas, A. M., and Cross, M. J. (2007). Vascular endothelial growth factor receptor-2: structure, function, intracellular signalling and therapeutic inhibition. Cell. Signal. 19, 2003-2012. doi: 10.1016/ j.cellsig.2007.05.013

Hong, S., and Banks, W. A. (2015). Role of the immune system in HIV-associated neuroinflammation and neurocognitive implications. Brain Behav. Immun. 45, 1-12. doi: 10.1016/j.bbi.2014.10.008

Hossain, M. I., Kamaruddin, M. A., and Cheng, H. C. (2012). Aberrant regulation and function of Src family tyrosine kinases: their potential contributions to glutamate-induced neurotoxicity. Clin. Exp. Pharmacol. Physiol. 39, 684-691. doi: $10.1111 / j .1440-1681.2011 .05621 . x$

Hu, G., Place, A. T., and Minshall, R. D. (2008). Regulation of endothelial permeability by Src kinase signaling: vascular leakage versus transcellular transport of drugs and macromolecules. Chem. Biol. Interact. 171, 177-189. doi: 10.1016/j.cbi.2007.08.006

Hudson, N., Powner, M. B., Sarker, M. H., Burgoyne, T., Campbell, M., Ockrim, Z. K., et al. (2014). Differential apicobasal VEGF signaling at vascular bloodneural barriers. Dev. Cell 30, 541-552. doi: 10.1016/j.devcel.2014.06.027

James, T., Nonnemacher, M. R., Wigdahl, B., and Krebs, F. C. (2016). Defining the roles for Vpr in HIV-1-associated neuropathogenesis. J. Neurovirol. 22, 403-415. doi: 10.1007/s13365-016-0436-5

Jeang, K. T., Chun, R., Lin, N. H., Gatignol, A., Glabe, C. G., and Fan, H. (1993). In vitro and in vivo binding of human immunodeficiency virus type 1 Tat protein and $\mathrm{Sp} 1$ transcription factor. J. Virol. 67, 6224-6233.

Kopke, A. K., Bonk, I., Sydow, S., Menke, H., and Spiess, J. (1993). Characterization of the NR1, NR2A, and NR2C receptor proteins. Protein Sci. 2, 2066-2076. doi: 10.1002/pro.5560021207

Krebs, F. C., Ross, H., McAllister, J., and Wigdahl, B. (2000). HIV-1associated central nervous system dysfunction. Adv. Pharmacol. 49, 315-385. doi: 10.1016/S1054-3589(00)49031-9

Krizanac-Bengez, L., Mayberg, M. R., and Janigro, D. (2004). The cerebral vasculature as a therapeutic target for neurological disorders and the role of shear stress in vascular homeostatis and pathophysiology. Neurol. Res. 26, 846-853. doi: 10.1179/016164104X3789

Krogh, K. A., Wydeven, N., Wickman, K., and Thayer, S. A. (2014). HIV-1 protein Tat produces biphasic changes in NMDA-evoked increases in intracellular $\mathrm{Ca}^{2+}$ concentration via activation of Src kinase and nitric oxide signaling pathways. J. Neurochem. 130, 642-656. doi: 10.1111/jnc.12724

Kukkonen, S., Martinez-Viedma Mdel, P., Kim, N., Manrique, M., and Aldovini, A. (2014). HIV-1 Tat second exon limits the extent of Tat-mediated modulation of interferon-stimulated genes in antigen presenting cells. Retrovirology 11:30 doi: 10.1186/1742-4690-11-30

Lee, C. H., Lu, W., Michel, J. C., Goehring, A., Du, J., Song, X., et al. (2014). NMDA receptor structures reveal subunit arrangement and pore architecture. Nature 511, 191-197. doi: 10.1038/nature13548

Li, W., Huang, Y., Reid, R., Steiner, J., Malpica-Llanos, T., Darden, T. A., et al. (2008). NMDA receptor activation by HIV-Tat protein is clade dependent. J. Neurosci. 28, 12190-12198. doi: 10.1523/JNEUROSCI.3019-08.2008

Li, W., Li, G., Steiner, J., and Nath, A. (2009). Role of Tat protein in HIV neuropathogenesis. Neurotox. Res. 16, 205-220. doi: 10.1007/s12640-0099047-8

Lim, S. P., and Garzino-Demo, A. (2000). The human immunodeficiency virus type 1 Tat protein up-regulates the promoter activity of the beta-chemokine monocyte chemoattractant protein 1 in the human astrocytoma cell line U-87 MG: role of SP-1, AP-1, and NF-kB consensus sites. J. Virol. 74, 1632-1640. doi: 10.1128/JVI.74.4.1632-1640.2000

Liu, D. Z., Ander, B. P., Xu, H., Shen, Y., Kaur, P., Deng, W., et al. (2010). Bloodbrain barrier breakdown and repair by Src after thrombin-induced injury. Ann. Neurol. 67, 526-533. doi: 10.1002/ana.21924

Logsdon, A. F., Lucke-Wold, B. P., Turner, R. C., Huber, J. D., Rosen, C. L., and Simpkins, J. W. (2015). Role of microvascular disruption in brain damage from traumatic brain injury. Compr. Physiol. 5, 1147-1160. doi: $10.1002 /$ cphy.c140057

Lord, R. V. (1997). Anorectal surgery in patients infected with human immunodeficiency virus: factors associated with delayed wound healing. Ann. Surg. 226, 92-99. doi: 10.1097/00000658-199707000-00013

Louboutin, J. P., and Strayer, D. S. (2012). Blood-brain barrier abnormalities caused by HIV-1 gp120: mechanistic and therapeutic implications. ScientificWorldJournal 2012:482575. doi: 10.1100/2012/482575

Lu, W. Y., Xiong, Z. G., Lei, S., Orser, B. A., Dudek, E., Browning, M. D., et al. (1999). G-protein-coupled receptors act via protein kinase C and Src to regulate NMDA receptors. Nat. Neurosci. 2, 331-338. doi: 10.1038/7243

Majello, B., De Luca, P., Hagen, G., Suske, G., and Lania, L. (1994). Different members of the Sp1 multigene family exert opposite transcriptional regulation of the long terminal repeat of HIV-1. Nucleic Acids Res. 22, 4914-4921. doi: $10.1093 / \mathrm{nar} / 22.23 .4914$

Maubert, M. E., Pirrone, V., Rivera, N. T., Wigdahl, B., and Nonnemacher, M. R. (2015). Interaction between tat and drugs of abuse during HIV1 infection and central nervous system disease. Front. Microbiol. 6:1512. doi: $10.3389 /$ fmicb. 2015.01512

McCarthy, S. D., Sakac, D., Neschadim, A., and Branch, D. R. (2016). c-SRC protein tyrosine kinase regulates early HIV-1 infection post-entry. AIDS 30, 849-858. doi: 10.1097/QAD.0000000000001028

Mediouni, S., Darque, A., Baillat, G., Ravaux, I., Dhiver, C., Tissot-Dupont, H., et al. (2012). Antiretroviral therapy does not block the secretion of the human immunodeficiency virus tat protein. Infect. Disord. Drug Targets 12, 81-86. doi: $10.2174 / 187152612798994939$

Meucci, O., and Miller, R. J. (1996). gp120-induced neurotoxicity in hippocampal pyramidal neuron cultures: protective action of TGF-beta1. J. Neurosci. 16, $4080-4088$.

Miller-Jensen, K., Skupsky, R., Shah, P. S., Arkin, A. P., and Schaffer, D. V. (2013). Genetic selection for context-dependent stochastic phenotypes: Sp1 and TATA mutations increase phenotypic noise in HIV-1 gene expression. PLoS Comput. Biol. 9:e1003135. doi: 10.1371/journal.pcbi.1003135

Mitola, S., Soldi, R., Zanon, I., Barra, L., Gutierrez, M. I., Berkhout, B., et al. (2000). Identification of specific molecular structures of human immunodeficiency virus type 1 Tat relevant for its biological effects on vascular endothelial cells. $J$. Virol. 74, 344-353. doi: 10.1128/JVI.74.1.344-353.2000

Miyamoto, S., Hara, T., Tabei, Y., Honma, H., Kondo, T., and Oka, S. (2006). Aneurysmal subarachnoid hemorrhage in a patient with human immunodeficiency virus type 1 infection. Case report. Neurol. Med. Chir. 46, 348-52. doi: 10.2176/nmc.46.348

Morin-Brureau, M., Lebrun, A., Rousset, M. C., Fagni, L., Bockaert, J., de Bock, F., et al. (2011). Epileptiform activity induces vascular remodeling and zonula occludens 1 downregulation in organotypic hippocampal cultures: role of VEGF signaling pathways. J. Neurosci. 31, 10677-10688. doi: 10.1523/JNEUROSCI.5692-10.2011

Nakagawa, S., Castro, V., and Toborek, M. (2012). Infection of human pericytes by HIV-1 disrupts the integrity of the blood-brain barrier. J. Cell. Mol. Med. 16, 2950-2957. doi: 10.1111/j.1582-4934.2012.01622.x 
Narute, P. S., and Smithgall, T. E. (2012). Nef alleles from all major HIV-1 clades activate Src-family kinases and enhance HIV-1 replication in an inhibitorsensitive manner. PLoS ONE 7:e32561. doi: 10.1371/journal.pone.0032561

Niu, F., Yao, H., Zhang, W., Sutliff, R. L., and Buch, S. (2014). Tat 101-mediated enhancement of brain pericyte migration involves platelet-derived growth factor subunit B homodimer: implications for human immunodeficiency virus-associated neurocognitive disorders. J. Neurosci. 34, 11812-11825. doi: 10.1523/JNEUROSCI.1139-14.2014

Obermeit, L. C., Beltran, J., Casaletto, K. B., Franklin, D. R., Letendre, S., Ellis, R., et al. (2017). Evaluating the accuracy of self-report for the diagnosis of HIV-associated neurocognitive disorder (HAND): defining "symptomatic" versus "asymptomatic" HAND. J. Neurovirol. 23, 67-78. doi: 10.1007/s13365-016-0474-z

Parsons, S. J., and Parsons, J. T. (2004). Src family kinases, key regulators of signal transduction. Oncogene 23, 7906-7909. doi: 10.1038/sj.onc.1208160

Pattarini, R., Pittaluga, A., and Raiteri, M. (1998). The human immunodeficiency virus-1 envelope protein gp120 binds through its V3 sequence to the glycine site of N-methyl-D-aspartate receptors mediating noradrenaline release in the hippocampus. Neuroscience 87, 147-157. doi: 10.1016/S0306-4522(98) 00125-0

Phipps, D. J., Read, S. E., Piovesan, J. P., Mills, G. B., and Branch, D. R. (1996). HIV infection in vitro enhances the activity of src-family protein tyrosine kinases. AIDS 10, 1191-1198. doi: 10.1097/00002030-199609000-00003

Pittaluga, A., Pattarini, R., Severi, P., and Raiteri, M. (1996). Human brain $\mathrm{N}$-methyl-D-aspartate receptors regulating noradrenaline release are positively modulated by HIV-1 coat protein gp120. AIDS 10, 463-468. doi: 10.1097/00002030-199605000-00003

Rao, V. R., Ruiz, A. P., and Prasad, V. R. (2014). Viral and cellular factors underlying neuropathogenesis in HIV associated neurocognitive disorders (HAND). AIDS Res. Ther. 11:13. doi: 10.1186/1742-6405-11-13

Reijerkerk, A., Kooij, G., van der Pol, S. M., Leyen, T., Lakeman, K., van Het Hof, B., et al. (2010). The NR1 subunit of NMDA receptor regulates monocyte transmigration through the brain endothelial cell barrier. J. Neurochem. 113, 447-453. doi: 10.1111/j.1471-4159.2010.06598.x

Reinecke, J., and Caplan, S. (2014). Endocytosis and the Src family of non-receptor tyrosine kinases. Biomol. Concepts 5, 143-155. doi: 10.1515/bmc-2014-0003

Ritchie, S., Boyd, F. M., Wong, J., and Bonham, K. (2000). Transcription of the human c-Src promoter is dependent on Spl, a novel pyrimidine binding factor $\mathrm{SPy}$, and can be inhibited by triplex-forming oligonucleotides. J. Biol. Chem. 275, 847-854. doi: 10.1074/jbc.275.2.847

Roberts, T. K., Buckner, C. M., and Berman, J. W. (2010). Leukocyte transmigration across the blood-brain barrier: perspectives on neuroAIDS. Front. Biosci. (Landmark Ed). 15, 478-536. doi: 10.2741/3631

Robertson, K. R., Smurzynski, M., Parsons, T. D., Wu, K., Bosch, R. J., Wu, J., et al. (2007). The prevalence and incidence of neurocognitive impairment in the HAART era. AIDS 21, 1915-1921. doi: 10.1097/QAD.0b013e32828e4e27

Rom, S., Pacifici, M., Passiatore, G., Aprea, S., Waligorska, A., Del Valle, L., et al. (2011). HIV-1 Tat binds to SH3 domains: cellular and viral outcome of Tat/Grb2 interaction. Biochim. Biophys. Acta 1813, 1836-1844. doi: 10.1016/j.bbamcr.2011.06.012

Rong, Y., Lu, X., Bernard, A., Khrestchatisky, M., and Baudry, M. (2001). Tyrosine phosphorylation of ionotropic glutamate receptors by Fyn or Src differentially modulates their susceptibility to calpain and enhances their binding to spectrin and PSD-95. J. Neurochem. 79, 382-390. doi: 10.1046/j.1471-4159.2001. 00565.x

Salmina, A. B., Inzhutova, A. I., Malinovskaya, N. A., and Petrova, M. M. (2010). Endothelial dysfunction and repair in Alzheimer-type neurodegeneration: neuronal and glial control. J. Alzheimers Dis. 22, 17-36. doi: 10.3233/JAD-2010-091690

Sen, B., and Johnson, F. M. (2011). Regulation of SRC family kinases in human cancers. J. Signal Transduct. 2011:865819. doi: 10.1155/2011/865819

Sharp, C. D., Hines, I., Houghton, J., Warren, A., Jackson, T. H., Jawahar, A., et al. (2003). Glutamate causes a loss in human cerebral endothelial barrier integrity through activation of NMDA receptor. Am. J. Physiol. Heart Circ. Physiol. 285, H2592-H2598. doi: 10.1152/ajpheart.00520.2003

Sharp, C. D., Houghton, J., Elrod, J. W., Warren, A., Jackson, T. H., Jawahar, A., et al. (2005). N-methyl-D-aspartate receptor activation in human cerebral endothelium promotes intracellular oxidant stress. Am. J. Physiol. Heart Circ. Physiol. 288, H1893-H1899. doi: 10.1152/ajpheart.01110.2003
Simioni, S., Cavassini, M., Annoni, J. M., Rimbault Abraham, A., Bourquin, I., Schiffer, V., et al. (2010). Cognitive dysfunction in HIV patients despite long-standing suppression of viremia. AIDS 24, 1243-1250. doi: 10.1097/QAD.0b013e3283354a7b

Song, L., Nath, A., Geiger, J. D., Moore, A., and Hochman, S. (2003). Human immunodeficiency virus type 1 Tat protein directly activates neuronal $\mathrm{N}$ methyl-D-aspartate receptors at an allosteric zinc-sensitive site. J. Neurovirol. 9, 399-403. doi: 10.1080/13550280390201704

Strazza, M., Pirrone, V., Wigdahl, B., and Nonnemacher, M. R. (2011). Breaking down the barrier: the effects of HIV-1 on the blood-brain barrier. Brain Res. 1399, 96-115. doi: 10.1016/j.brainres.2011.05.015

Sun, Z., Li, X., Massena, S., Kutschera, S., Padhan, N., Gualandi, L., et al. (2012). VEGFR2 induces c-Src signaling and vascular permeability in vivo via the adaptor protein TSAd. J. Exp. Med. 209, 1363-1377. doi: 10.1084/jem.20111343

Takenaga, Y., Takagi, N., Murotomi, K., Tanonaka, K., and Takeo, S. (2009). Inhibition of Src activity decreases tyrosine phosphorylation of occludin in brain capillaries and attenuates increase in permeability of the blood-brain barrier after transient focal cerebral ischemia. J. Cereb. Blood Flow Metab. 29, 1099-1108. doi: 10.1038/jcbfm.2009.30

Tang, L. J., Li, C., Hu, S. Q., Wu, Y. P., Zong, Y. Y., Sun, C. C., et al. (2012). S-nitrosylation of c-Src via NMDAR-nNOS module promotes c-Src activation and NR2A phosphorylation in cerebral ischemia/reperfusion. Mol. Cell. Biochem. 365, 363-377. doi: 10.1007/s11010-012-1280-4

Toborek, M., Lee, Y. W., Flora, G., Pu, H., Andras, I. E., Wylegala, E., et al. (2005). Mechanisms of the blood-brain barrier disruption in HIV-1 infection. Cell. Mol. Neurobiol. 25, 181-199. doi: 10.1007/s10571-004-1383-x

Tozzi, V., Balestra, P., Bellagamba, R., Corpolongo, A., Salvatori, M. F., ViscoComandini, U., et al. (2007). Persistence of neuropsychologic deficits despite long-term highly active antiretroviral therapy in patients with HIV-related neurocognitive impairment: prevalence and risk factors. J. Acquir. Immune Defic. Syndr. 45, 174-182. doi: 10.1097/QAI.0b013e318042elee

Trible, R. P., Emert-Sedlak, L., and Smithgall, T. E. (2006). HIV-1 Nef selectively activates Src family kinases Hck, Lyn, and c-Src through direct SH3 domain interaction. J. Biol. Chem. 281, 27029-27038. doi: 10.1074/jbc.M601128200

Urbinati, C., Bugatti, A., Giacca, M., Schlaepfer, D., Presta, M., and Rusnati, M. (2005). $\alpha_{\mathrm{V}} \beta_{3}$-integrin-dependent activation of focal adhesion kinase mediates NF- $\mathrm{KB}$ activation and motogenic activity by HIV-1 Tat in endothelial cells. J. Cell Sci. 118, 3949-3958. doi: 10.1242/jcs.02518

Wang, D., Melancon, J. K., Verbesey, J., Hu, H., Liu, C., Aslam, S., et al. (2013). Microvascular endothelial dysfunction and enhanced thromboxane and endothelial contractility in patients with HIV. J. AIDS Clin. Res. 4:267. doi: 10.4172/2155-6113.1000267

Wang, T., Rumbaugh, J. A., and Nath, A. (2006). Viruses and the brain: from inflammation to dementia. Clin. Sci. 110, 393-407. doi: 10.1042/CS20050278

Xin, K. Q., Hamajima, K., Hattori, S., Cao, X. R., Kawamoto, S., and Okuda, K. (1999). Evidence of HIV type 1 glycoprotein 120 binding to recombinant Nmethyl-D-aspartate receptor subunits expressed in a baculovirus system. AIDS Res. Hum. Retroviruses 15, 1461-1467. doi: 10.1089/088922299309973

Xu, H., Bae, M., Tovar-y-Romo, L. B., Patel, N., Bandaru, V. V., Pomerantz, D., et al. (2011). The human immunodeficiency virus coat protein gp120 promotes forward trafficking and surface clustering of NMDA receptors in membrane microdomains. J. Neurosci. 31, 17074-17090. doi: 10.1523/JNEUROSCI.4072-11.2011

Yu, X. M., and Salter, M. W. (1999). Src, a molecular switch governing gain control of synaptic transmission mediated by N-methyl-D-aspartate receptors. Proc. Natl. Acad. Sci. U.S.A. 96, 7697-7704. doi: 10.1073/pnas.96.14.7697

Zhang, X., Lanahan, A. A., and Simons, M. (2013). VEGFR2 trafficking: speed doesn't kill. Cell Cycle 12, 2163-2164. doi: 10.4161/cc.25536

Conflict of Interest Statement: The authors declare that the research was conducted in the absence of any commercial or financial relationships that could be construed as a potential conflict of interest.

Copyright (๑ 2017 Maubert, Wigdahl and Nonnemacher. This is an open-access article distributed under the terms of the Creative Commons Attribution License (CC $B Y)$. The use, distribution or reproduction in other forums is permitted, provided the original author(s) or licensor are credited and that the original publication in this journal is cited, in accordance with accepted academic practice. No use, distribution or reproduction is permitted which does not comply with these terms. 